See Article page 681

\section{Commentary: Old sins have long shadows}

\author{
Antonio Miceli, MD, PhD, and Mattia Glauber, MD
}

Acute kidney injury (AKI) is a frequent complication after cardiac surgery. ${ }^{1}$ Depending on its definition, AKI occurs in $3 \%$ to $30 \%$ of patients and is associated with increased mortality, morbidity, and increased health care costs. ${ }^{2}$ AKI has also an impact on long-term outcomes. Specifically, individuals with AKI have a 2-fold increased risk of new or progressive chronic kidney disease, a 4-fold increased risk of dialysis, and a 2-fold increased risk of death. ${ }^{3}$ The prevention of AKI and its consequences represents our goal to improve our results. It is required to know its physiopathology and adopt therapeutic strategies to mitigate its impact on long-term mortality and morbidity. In this regard, the effect of AKI on long-term outcome has been less investigated.

In this issue of the Journal, Cho and colleagues ${ }^{4}$ evaluated the association between AKI and chronic kidney disease (CKD) development, emphasizing the intermediary role of acute kidney disease (AKD). In patients with normal preoperative renal function undergoing heart valve surgery, AKI occurred in $23.9 \%$ of patients. Among these, the prevalence of AKD and CKD was $15.1 \%$ and $12.5 \%$, which was greater compared with those patients who did not develop AKI ( $4.7 \%$ and $4.2 \%)$. Interestingly, $88 \%$ of patients recovered form AKI. As expected, AKI increased the risk of AKD and CKD at 3 and 12 months. The new information is that patients who recovered early (within 3 days) from AKI are still at risk of developing renal failure. Specifically, these patients had still 3-fold increased risk of developing AKD and CKD at follow-up.

The relationship was more evident in patients with preexisting renal disease. This study implies the importance of adopting some therapeutic strategies in patients who

\footnotetext{
From the Minimally Invasive Cardiac Surgery Department, Istituto Clinico San'Ambrogio, Milan, Italy.

Disclosures: Authors have nothing to disclose with regard to commercial support.

Received for publication Nov 5, 2019; revisions received Nov 5, 2019; accepted for publication Nov 7, 2019; available ahead of print Nov 28, 219

Address for reprints: Antonio Miceli, MD, PhD, Minimally Invasive Cardiac Surgery

Department, Istituto Clinico San'Ambrogio, Via LG Faravelli 16, Milano, Italy

(E-mail: antoniomiceli79@alice.it).

J Thorac Cardiovasc Surg 2021;161:691-2

0022-5223/ $\$ 36.00$

Copyright (C) 2019 by The American Association for Thoracic Surgery

https://doi.org/10.1016/j.jtcvs.2019.11.013
}

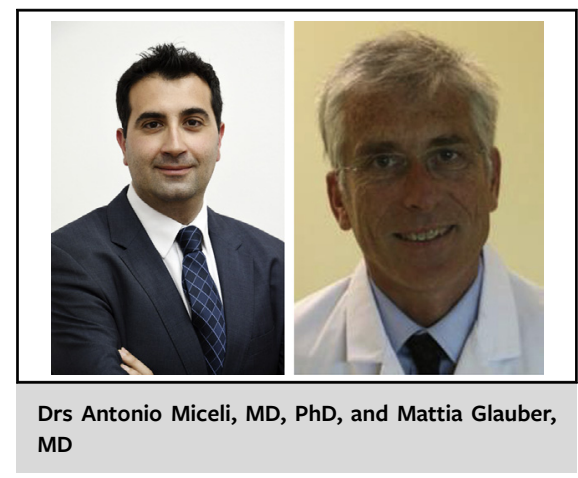

CENTRAL MESSAGE

Patients with normal renal func-

tion who recover from AKI are

still at risk for renal failure.

experienced AKI, especially in those with a normal preoperative renal function who recovered completely from AKI. In addition, authors highlighted the role of cardiac function in predicting long-term renal failure. Nevertheless, this study presents several potential confounding factors, which limit results. This study was conducted in patients undergoing valve surgery and does not reflect the overall population of cardiac surgery. The mechanism of valve disease affects the cardiac function in a different manner (concentric vs eccentric hypertrophy), especially in the presence of left ventricular dilatation. Then, some of these patients underwent myocardial revascularization for coronary disease, a well-known risk factor for worse early and long-term outcome. A more homogeneous population is required to give a better understanding of the problem. Heart failure was found to be a predictor of AKI and CKD but not of AKD at 3 months.

Heart failure is a complex and multifactorial disease that includes plenty of signs and symptoms of left ventricular dysfunction. Despite being well defined, the inclusion of more objective variables, such as left ventricular dimension, right ventricular function, and New York Heart Association class, might have given different results. Finally, a perspective is required. AKI continues to be a serious problem after cardiac surgery and associated with poor outcomes. We learned that patients with normal renal function who recover from AKI are still at risk for renal failure. Therapeutic strategies, which include the control of cardiac and renal modifiable risk factors as well as early referral to nephrologist specialist, are required to improve patient's survival. 


\section{References}

1. Mariscalco G, Lorusso R, Dominici C, Renzulli A, Sala A. Acute kidney injury: a relevant complication after cardiac surgery. Ann Thorac Surg. 2011;92:1539-47.

2. Miceli A. Proteinuria is an equivalent marker for low renal function. J Thorac Cardiovasc Surg. 2015;149:900-1.

3. See EJ, Jayasinghe K, Glassford M, Johnson DW, Polkinghorne KR, Toussaint ND, et al. Long-term risk of adverse outcomes after acute kidney injury: a systematic review and meta-analysis of cohort studies using consensus definitions of exposure. Kidney Int. 2019;95: 160-72.

4. Cho JS, Shim JK, Lee S, Song JW, Choi N, Lee S, et al. Chronic progression of cardiac surgery associated acute kidney injury: intermediary role of acute kidney disease. J Thorac Cardiovasc Surg. 2021;161: 681-8.e3. 